\section{COMPLEJO DE OFICINAS MADRID/ESPAÑA}

\author{
José A. Domínguez Salazar \\ José A. Domínguez Urquijo y \\ Manuel Domínguez Urquijo, \\ Arquitectos
}

$145-111$

\section{SINOPSIS}

Con la remodelación de un antiguo edificio del siglo XVI, la reconstrucción de otro del siglo XIX y realizando un tercero de nuevo diseño, se ha conformado un conjunto interrelacionado que alberga las dependencias de la nueva Sede del Banco Urquijo.

El grupo de edificios, que alcanza una superficie construida próxima a los $40.000 \mathrm{~m}^{2}$, ha recibido distintos tratamientos, de acuerdo con las diferentes caracteristicas de las tres construcciones. Se ha conseguido aunar siempre la adecuada flexibilidad de utilización con la integrada armonía del conjunto, tanto entre sí como con las construcciones colindantes llegándose, en este sentido, hasta la nueva ordenación de la Plaza del Rey, punto focal de todas las edificaciones.

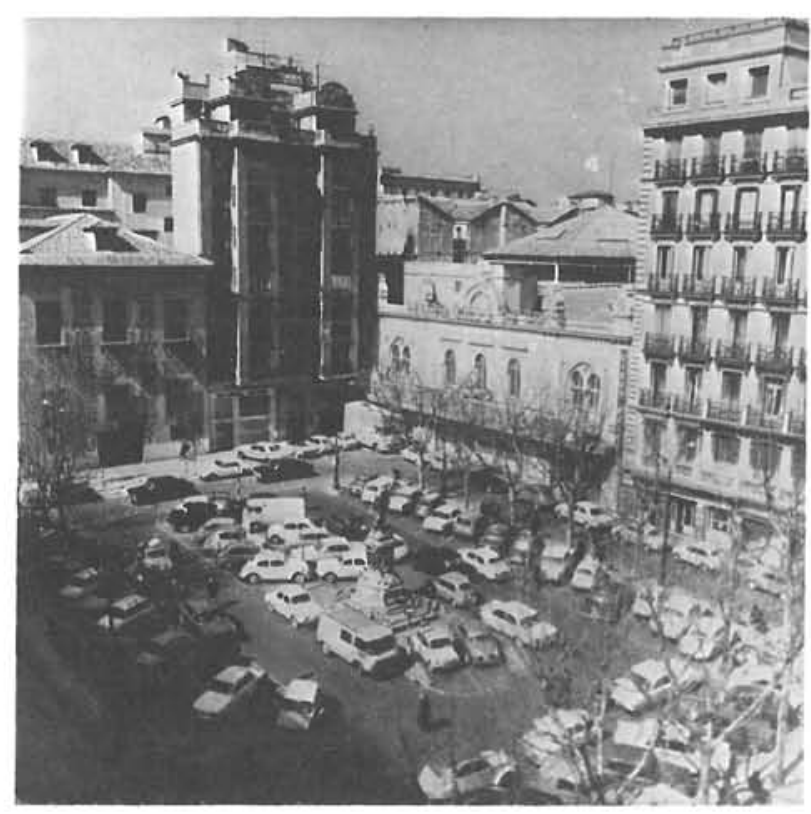

Estado primitivo de la plaza

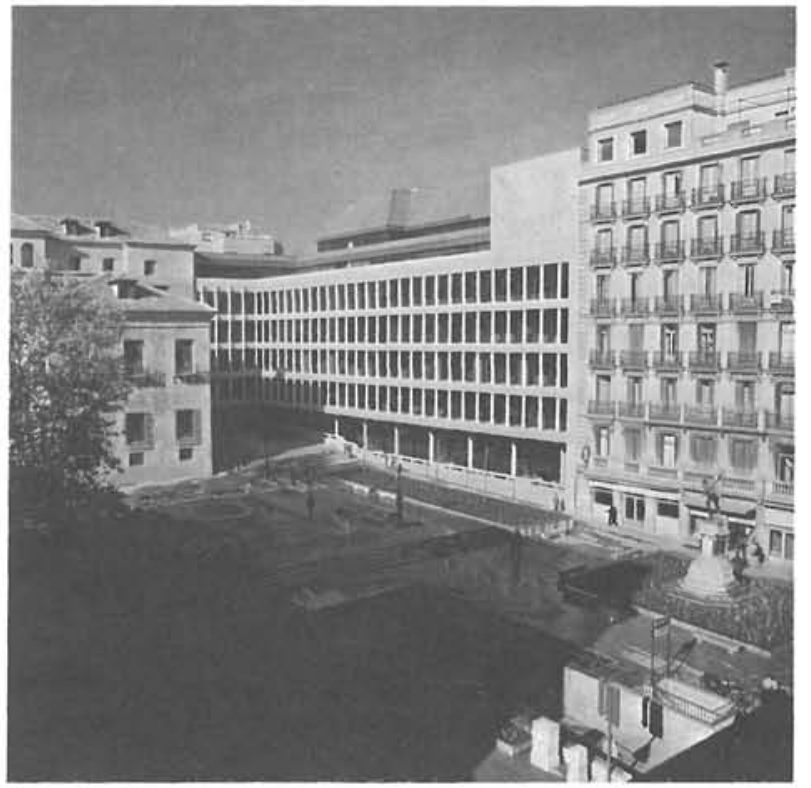

Remodelación de la plaza

La nueva Sede del Banco Urquijo se integra en un conjunto formado por tres edificios de caracteristicas externas diferentes, interrelacionados en varias plantas bajo y sobre rasante.

Uno de los edificios, la Casa de las 7 Chimeneas, es una construcción original del S. XVI, que pasó por remodelaciones y usos diferentes y fue puesta en servicio por última vez en 1958; el segundo corresponde a la reconstrucción de un edificio del S. XIX, que habia sido totalmente demolido; y el último, situado entre los dos anteriores, es una construcción de nuevo diseño.

Destacando en la antigua fisonomía de la Plaza del Rey, la Casa de las 7 Chimeneas quedaba, no obstante, empobrecida por la presencia de un edificio que estaba adosado a su fachada septentrional y dislocaba totalmente su volumen. En el otro lado de la plaza se encontraba el edificio perteneciente al Circo Price. Las viviendas que lo rodeaban mostraban sus medianerias, constituyendo pantallas urbanas que agredian las perspectivas desde y sobre la plaza. Por otra parte, la vida y el funcionamiento del circo se hacia cada vez más difícil por los trastornos circulatorios que ocasionaba el acceso al mismo, a través de las estrechas calles circundantes, tanto de los camiones y demás medios auxiliares como de las personas o animales que trabajaban en su interior. Estas consideraciones condujeron a la demolición de las dos edificaciones, iniciándose la elaboración del nuevo proyecto a partir de ese momento. 
La idea fundamental que presidió la confección del mismo fue la de aunar la realización de un inmueble actual y flexible en sus usos, con la puesta en valor, con toda su personalidad, del histórico edificio de la Casa de las 7 Chimeneas, elemento pricipal del entorno urbano de la Plaza del Rey. Esta intención se concretó en los siguientes puntos:

1. ${ }^{\circ}$ Realzar la Casa de las 7 Chimeneas, dejando exento su volumen primitivo.

2. Respetar el cromatismo del entorno, la proporción de huecos y fachadas y la altura de las cornisas dominantes de las edificaciones contiguas.

3. - Ocultar las medianerias de las fincas colindantes y componer una fachada con la severa austeridad de la Casa de las 7 Chimeneas, evitando composiciones de uno u otro signo que pudieran desvirtuar su auténtica realidad o distorsionaran el conjunto.

4. - Rematar el edificio con unos cuerpos que, sin tomar protagonismo en la perspectiva inmediata de la plaza, armonizaran formalmente con las cubiertas de la Casa de las 7 Chimeneas $y$, además, alojaran en su interior los elementos mecánicos de las instalaciones del edificio que fuese necesario situar en la última planta.

5. ${ }^{\circ}$ Aumentar el espacio ambiental de la plaza a nivel peatonal, retranqueando la construcción en plata baja.

Para todo ello, en la composición de la planta general del conjunto se empezo por crear una nueva Ionja lateral paralela al eje mayor de la Casa de las 7 Chimeneas adosada a ésta que, con la ya existente, dejaba exento el volumen principal de este edificio. El nuevo espacio asi obtenido aumenta la superficie de la Plaza del Rey, sirve de "antesala exterior" para la entrada al nuevo edificio y origina un paso peatonal que comunica la calle de Colmenares con la plaza.

Definida la composición de la planta general, se fijo la altura de los nuevos volúmenes a construir de acuerdo con las lineas compositivas generales de la Casa de las 7 Chimeneas, teniendo en cuenta la necesidad de ocultar las medianerias de las fincas contiguas.

Como se ha dicho anteriormente, la idea de no distorsionar la realidad de la Casa de las 7 Chimeneas prevalecio sobre cualquier otra consideración. En consecuencia, la función del nuevo edificio se expreso exteriormente en un lenguaje arqui-

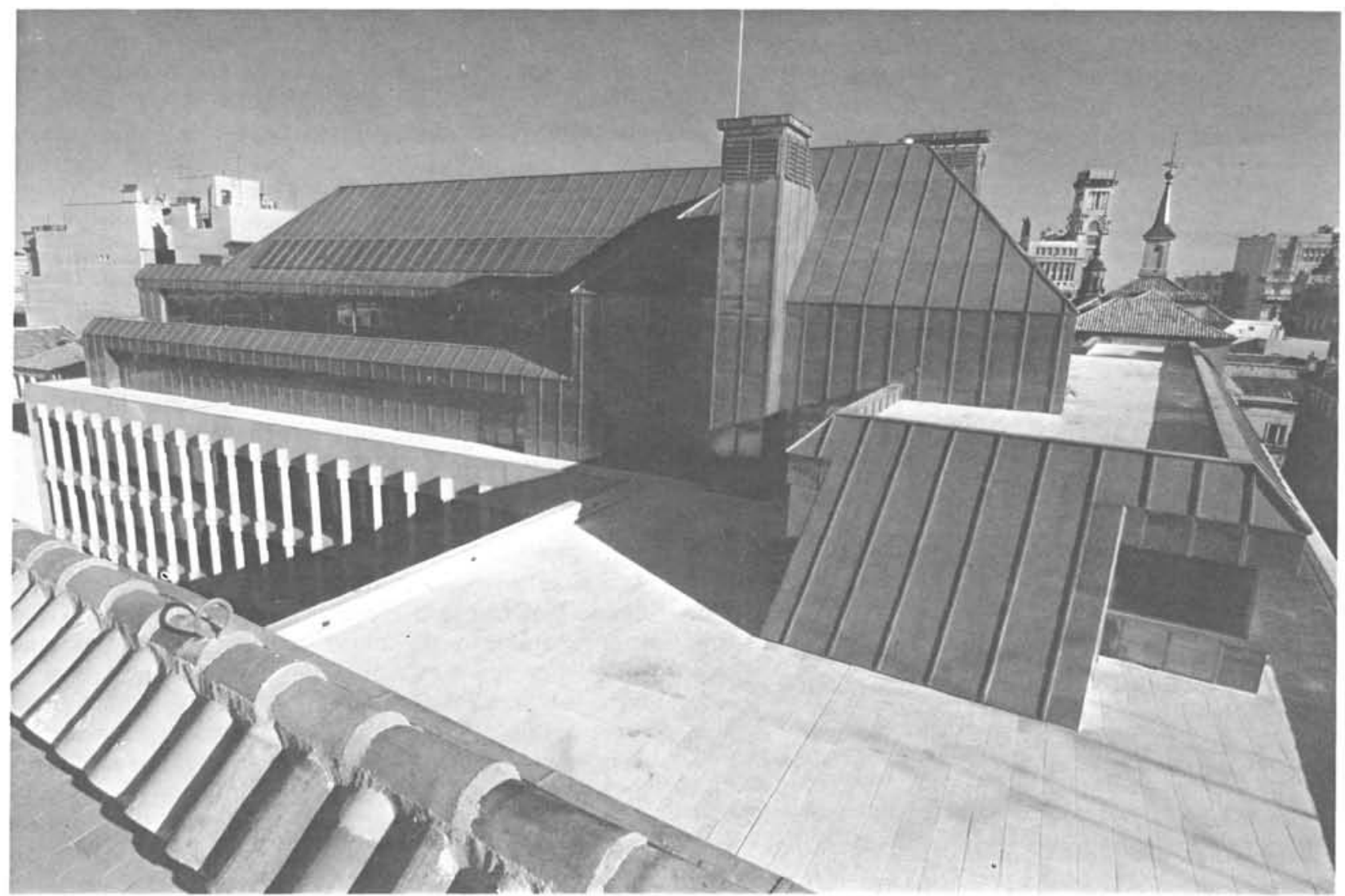


tectónico actual pero empleando una composición tradicional, como la superposición de "loggias" (indicadas, además, por las largas longitudes de fachada a la Plaza del Rey y calle Colmenares), que componen una doble fachada. Estas fachadas son resistentes y están construidas a base de pequeños pilares ordenados según un módulo de $1,80 \mathrm{~m}$, que recogen todas las cargas verticales correspondientes a la primera crujia, y transmiten los esfuerzos a pilares de hormigón, de sección circular, en planta baja. El retranqueo de cerramientos en fachada se hace aquí más evidente pues se crean unos patios ingleses de doble altura que aumentan el espacio ambiental de la Plaza del Rey y calle de Colmenares, iluminan los locales de semisotano y transforman el factor cuantitativo de la falta de aprovechamiento de la planta baja en factor cualitativo, al facilitar un entorno que ennoblece el espacio perimetral del edificio.

La integración se alcanza y completa mediante la armonia cromática que proporciona el empleo, con material de fachada, del granito rosa abujardado y por el empleo de planchas de cobre en los faldones inclinados de la cubierta, que armonizan, tanto en cromatismo como en pendiente, con la cubierta de la Casa de las 7 Chimeneas.

El resultado de estos planteamientos es la clara diferenciación, dentro de la integración alcanzada, de los edificios que componen el conjunto, en el que el nuevo sirve de telón de fondo del que se desea resaltar. De esta forma, la Casa de las 7 Chimeneas queda destacada, en su nitido volumen, contra un fondo de ritmos horizontales con su correspondiente vibración de claroscuros.

Interiormente se pretendió la creación de un espacio flexible de forma que las posibles modificaciones a introducir durante la vida del edificio no alteren sustancialmente el diseño inicial y se puedan realizar con escaso coste. El edificio está modulado de acuerdo con unidades de $0,90 \mathrm{~m}$, submodulo del estructural del edificio. El hecho de que los cerramientos estén retranqueados de la primera línea de crujia, permite la distribución de los módulos de trabajo en ambos sentidos. Todos los puestos de trabajo están dotados de las conexiones eléctricas, telefónicas e informáticas necesarias.

Se puso especial cuidado en el diseño de las instalaciones del edificio, de forma que éstas recuperaran y reconvirtieran la energia de modo que la aportación energética exterior fuera mínima.

En los acabados interiores se emplearon distintos materiales según los casos; así, en el vestíbulo de entrada y en el núcleo de ascensores se dispuso granito rosáceo abujardado, mientras que en las

Perspectiva aérea del conjunto.

Calle San Marcos esquina a Colmenares

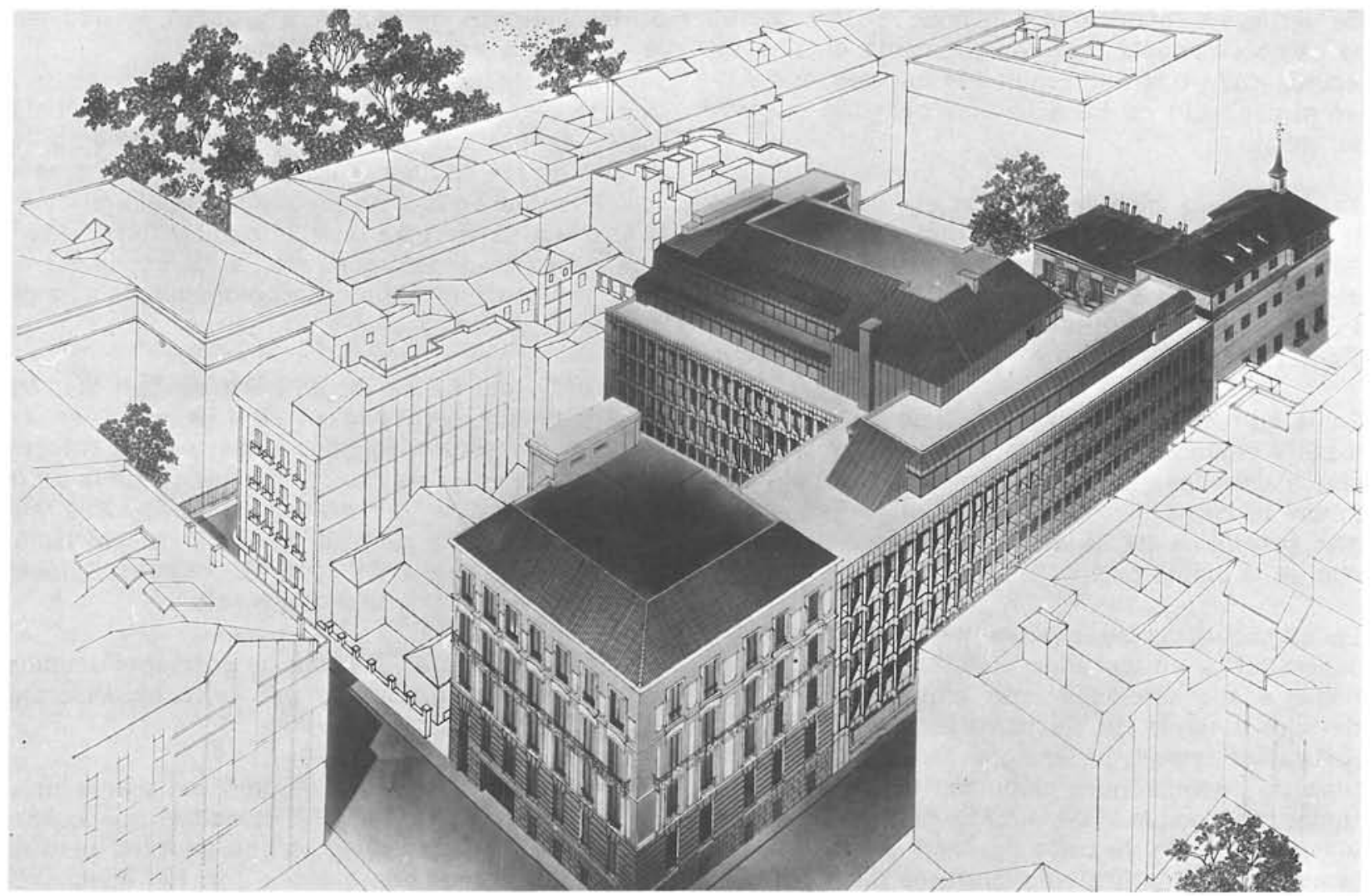




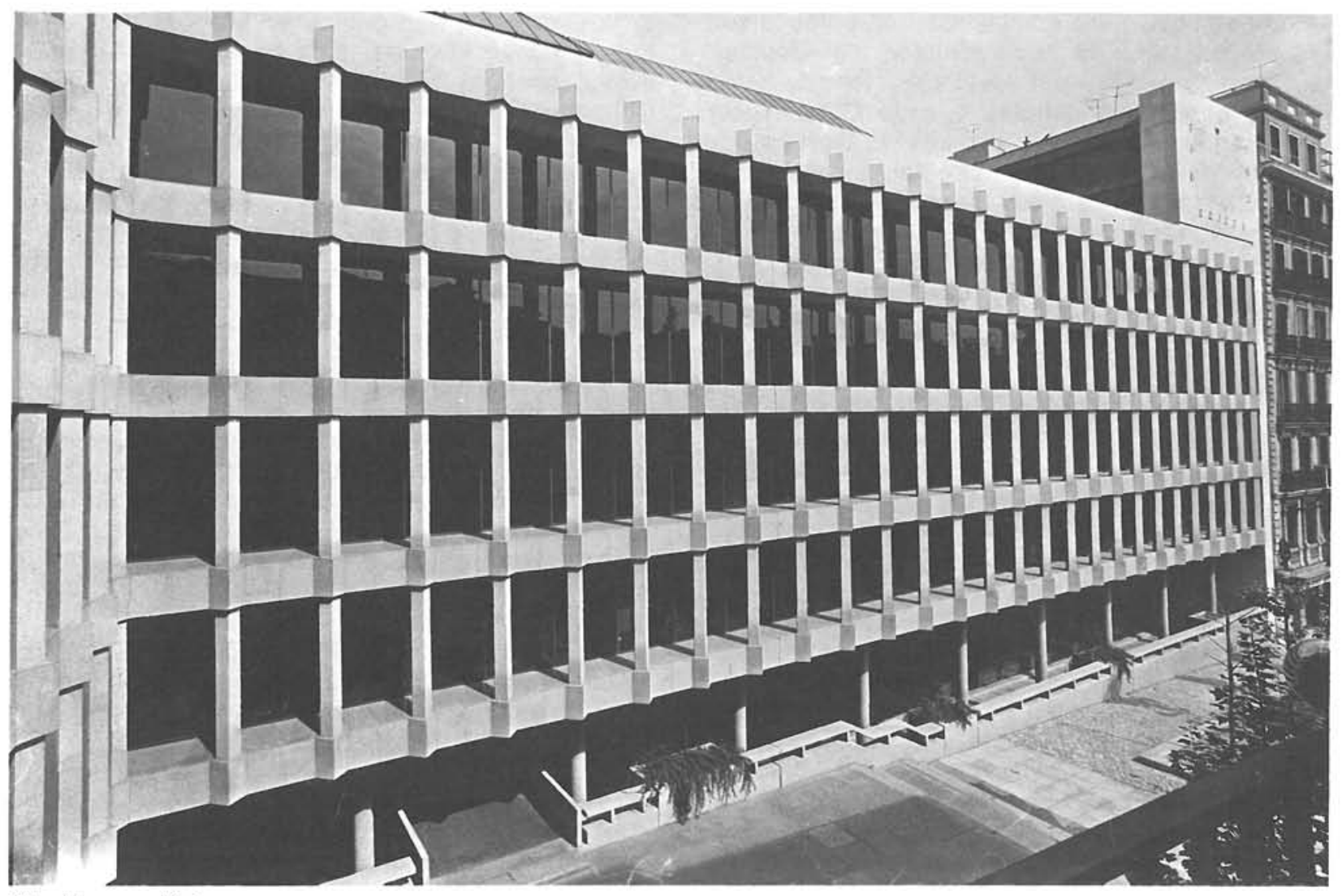

Vista del nuevo edificio

naves de trabajo y en los despachos en general se utilizo un "corcho linoleo" para revestir paramentos verticales, mamparas y pilares. En los suelos se coloco moqueta, que se fragmenta en una dirección cada $0,90 \mathrm{~m}$, según los canales que alojan el cableado de instalaciones para los puestos de trabajo.

Se diseño un mobiliario especial, controlándose su colorido y dimensiones. El mobiliario clásico o de estilo que posee la propiedad se integro en despachos o en lugares estratégicos de las áreas abiertas para enriquecer o formalizar los ambientes.

En la estructura del nuevo edificio se emplearon losas y pilares de hormigón armado. Las fachadas son resistentes, con pilares metálicos que transmiten su carga a los pilares circulares de hormigón armado, a través de la losa reforzada del techo de la planta baja.

La climatizacion se procura mediante fancoils a cuatro tubos en fachadas y sistema de caudal variable a alta velocidad, con impulsión y retorno del aire a través de las pantallas de iluminación. Se autoabastece de energía proveniente de las fuentes internas (luz, máquina, etc.), hasta una temperatura exterior de $-3^{\circ} \mathrm{C}$, con autonomia de almacenamiento de calor de hasta 3 dias. Cuenta también con producción simultánea de frio y calor por bomba de calor y con sistemas de compensacion exterior que permiten utilizar el aire exterior en los periodos de primavera y otono, en los que la temperatura de éste es intermedia.

Las instalaciones están controladas por un ordenador central que detecta, en todo momento, el estado de los equipos y las condiciones ambientales. Respondiendo a un programa, ordena el cierre o apertura de válvulas o circuitos eléctricos, arranque o parada de equipos, etc., para conseguir en todo momento el optimo aprovechamiento energético y mecánico.

El edificio del S. XIX en la calle de San Marcos, se encontraba derribado en su totalidad, con excepción del zócalo. Existian unos planos, fotografias generales y restos de cerrajería como datos para realizar una interpretación. Con estos elementos se llevó a cabo un ejercicio de restitución en el que se diseñaron cornisas, molduras, recercados de ventanas, carpinterias, etc.

En la medianería al descubierto correspondiente a la calle San Marcos, se proyecto un "trompe d'oeil» simplificado al máximo.

En el interior del edificio se creo, en planta baja, un salon de actos con 279 asientos, de acuerdo con la diagonal del solar, lo que permitio resolver satisfactoriamente los enlaces con los huecos de 

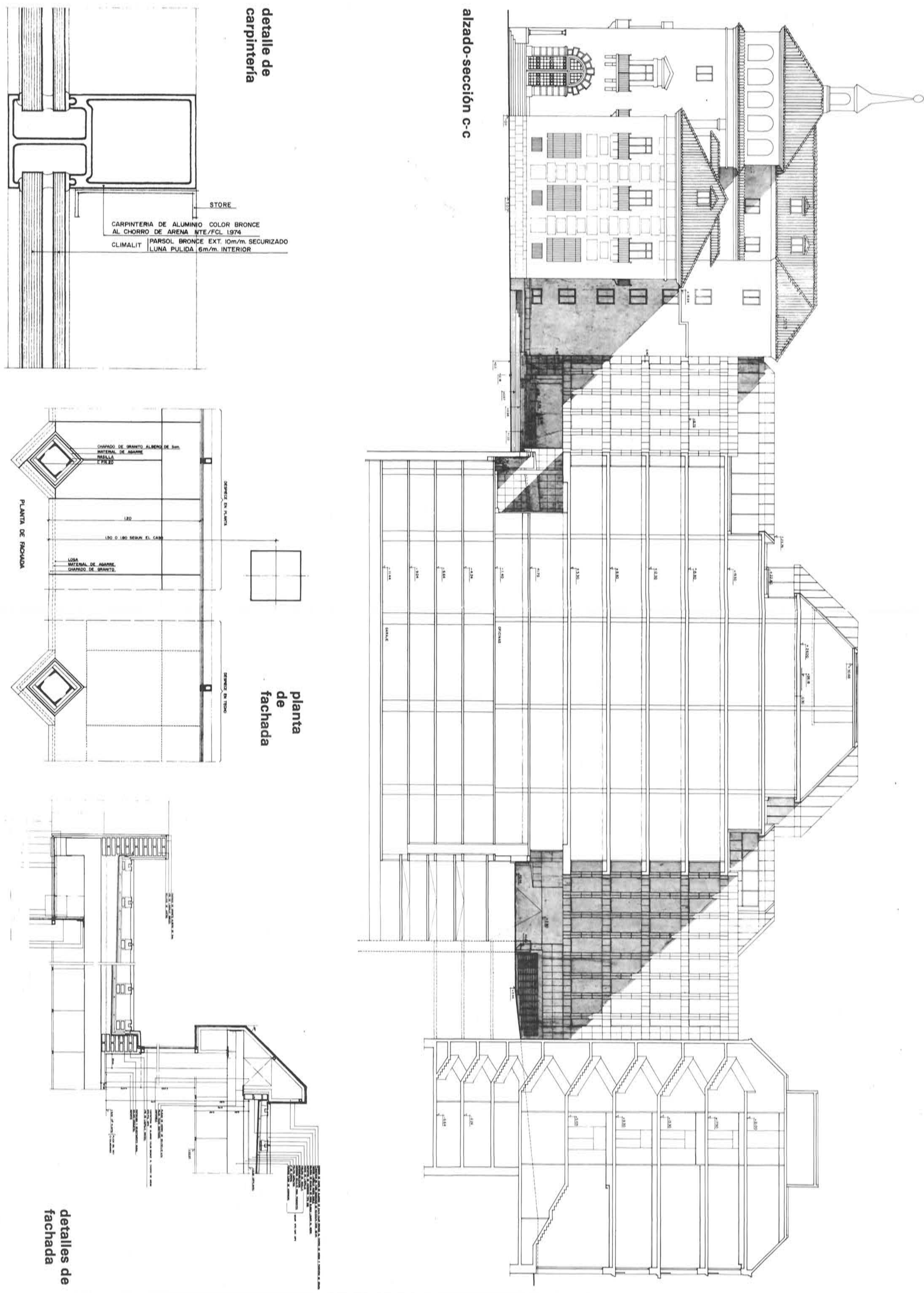


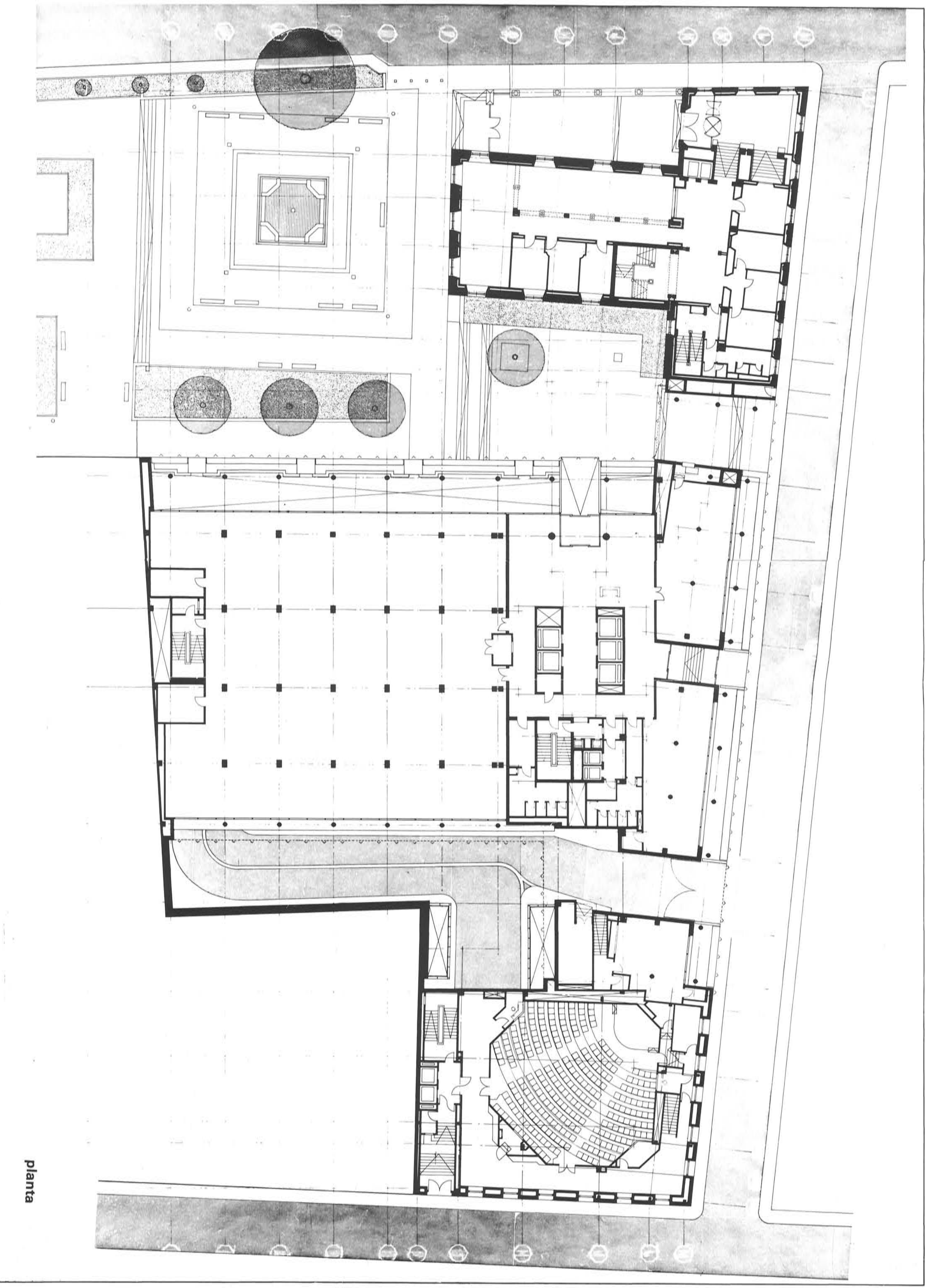




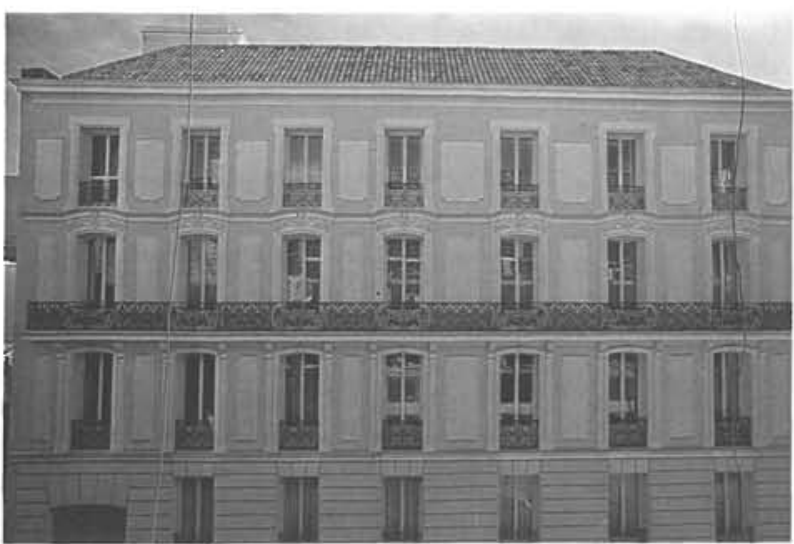

El edificio vuelto a construir, calle San Marcos

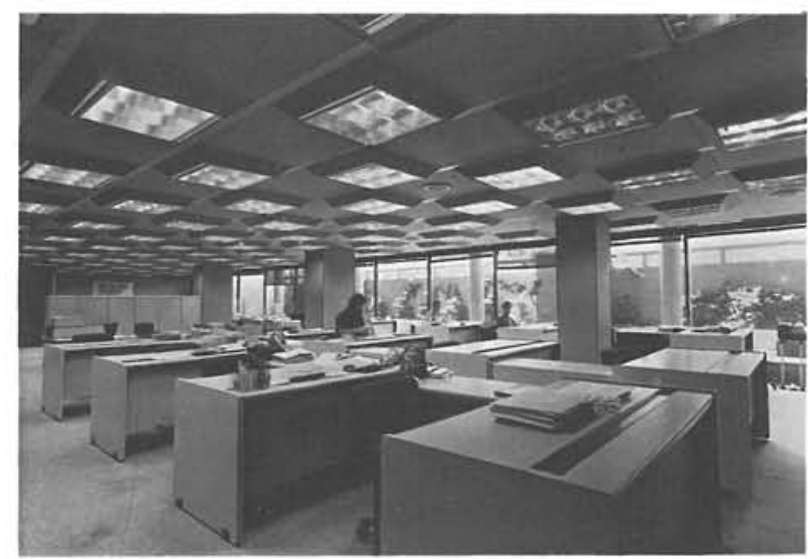

Nuevo Edificio. Nivel semisótano

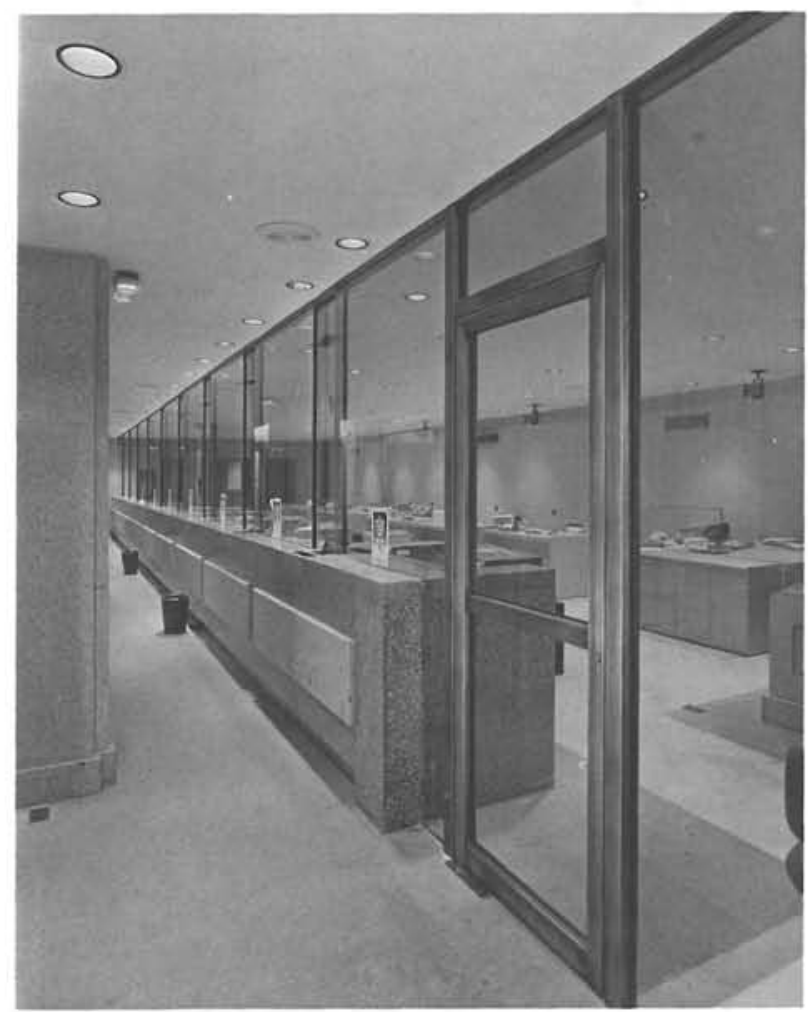

Ventanillas de caja. Casa de las 7 Chimeneas

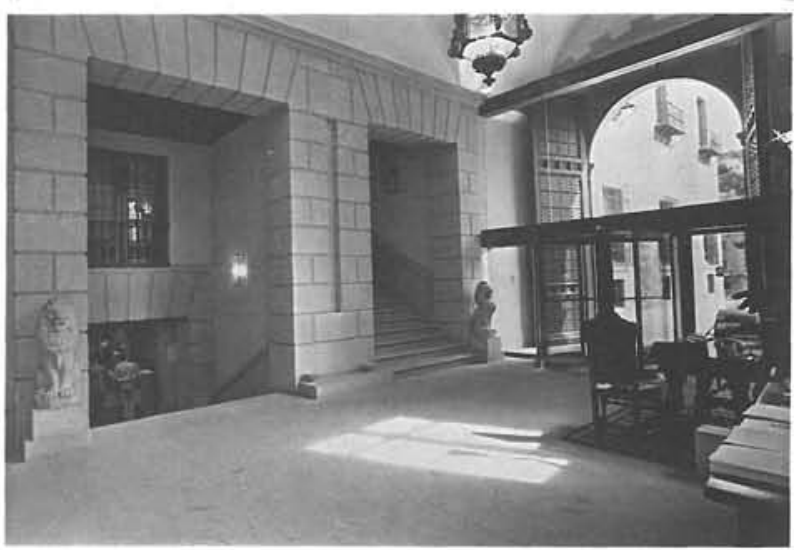

La Casa de las 7 Chimeneas. Hall de acceso

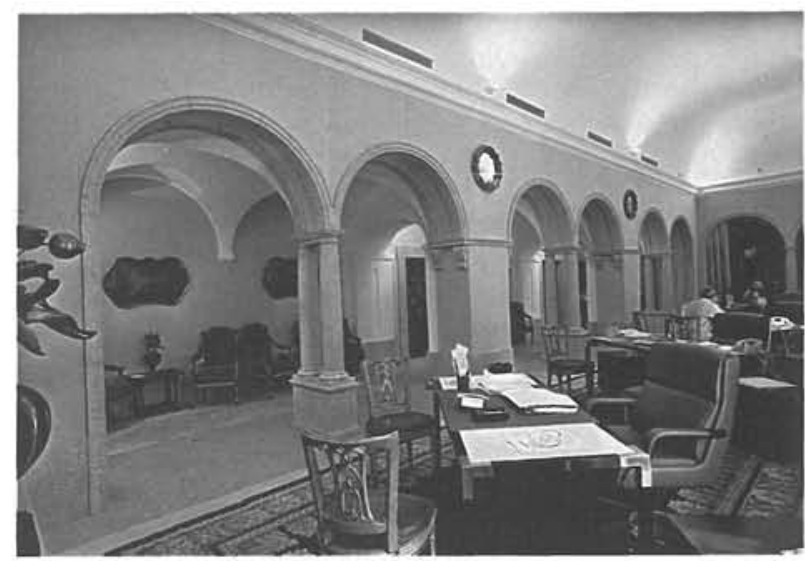

Espacios interiores de nueva creación. Casa de las 7 Chimeneas

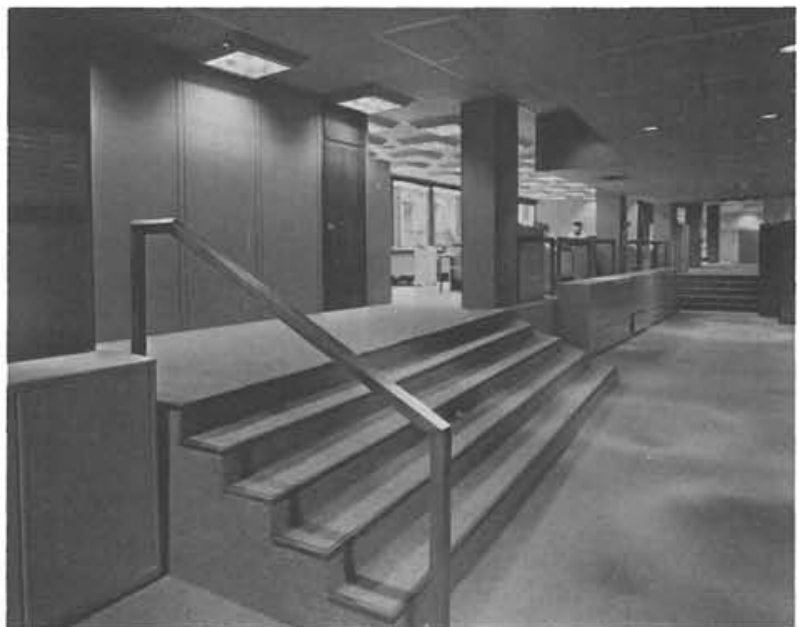

Interior del nuevo edificio

fachada. Las otras plantas se destinaron a oficinas.

La Casa de las 7 Chimeneas se ha remodelado interiormente en función de su destino actual como oficina principal del banco.

Las plantas sobre las que se ha actuado estaban parcialmente compartimentadas en despachos. La planta baja era un garaje. El criterio seguido es el 
de dejarlas diáfanas, enriqueciendo los espacios surgidos con elementos arquitectónicos de diseño clásico. La planta baja se destina ahora a patio de operaciones de la entidad.

Se han aprovechado el mobiliario de época y los cuadros que tenia la propiedad en su antigua sede social, completándose con algunos muebles de diseño moderno que aligeran y dan mayor funcionalidad a los servicios que se prestan. En general, se han mantenido áreas abiertas que revalorizan las proporciones internas del edificio.

Al recuperarse la fachada lateral, oculta por el edificio del S. XIX, se han restituido sus huecos y paramentos. Del mismo modo, la supresión del garaje en planta baja condujo a recomponer su fachada a la Plaza del Rey.

Por último, la disposición del nuevo conjunto incidia sobre la ordenación de la Plaza del Rey, Io que llevo a proyectar su remodelación.

En la nueva ordenación, las diferentes rasantes y niveles de las calles Colmenares, de las Infantas y del Barquillo, determinan, dentro de las obligadas pendientes, tres plataformas principales. En la primera, a partir de la calle Barquillo, quedan comprendidas la entrada al aparcamiento subterráneo y la estatua del Teniente Ruiz, obra de Mariano Benlliure; en la segunda se ha dispuesto una fuente que centra la plaza, la Casa de las 7 Chimeneas y el nuevo edificio; finalmente, en la tercera plataforma, de acceso al edificio y unión con la calle Colmenares, es foco importante de atraccion la nueva escultura de Eduardo Chillida. Estas tres bancadas hacen posible, dentro de la unidad ambiental de la plaza, la convivencia de elementos tan dispares.

En toda la plaza, pavimentada con grandes losas de granito e iluminada con farolas "Fernandinas", se han colocado bancos de piedra de diseño y material coherente con el conjunto. El criterio compositivo se extiende al diseño de la fuente y de la barandilla que protege la entrada al aparcamiento.

Se ha conservado el magnífico plátano existente y los magnolios que separan la plaza del tráfico rodado de la calle de las Infantas. Se han plantado otros plátanos en las nuevas zonas ajardinadas proyectadas y diversas especies tapizantes y arbustivas.

La plaza asi remozada sirve, al modo tradicional, de gran Ionja o vestíbulo peatonal ambiental de la Casa de las 7 Chimeneas y ennoblece la encrucijada formada por las calles del Barquillo y de las Infantas, en las proximidades de la calle de Alcalá.

\begin{tabular}{|ll|}
\hline colaboradores: & \\
José M. Martínez de Luco y & Leandro Silva \\
J. Pérez Martín & Paisajista \\
Consultores de Instalaciones & \\
$\begin{array}{l}\text { Pedro J. Blanco y } \\
\text { R. Buzón }\end{array}$ & José M. Calderón \\
Consultores de Estructura & Ingeniero Civil \\
$\begin{array}{l}\text { Francisco Muñoz y G. Martínez Pita } \\
\text { Decoración }\end{array}$ & Manuel López García y Faustino Olmos \\
\hline
\end{tabular}

Remodelación de la plaza.

Paso peatonal de comunicación plaza del Rey y calle Colmenares bajo el nuevo edificio

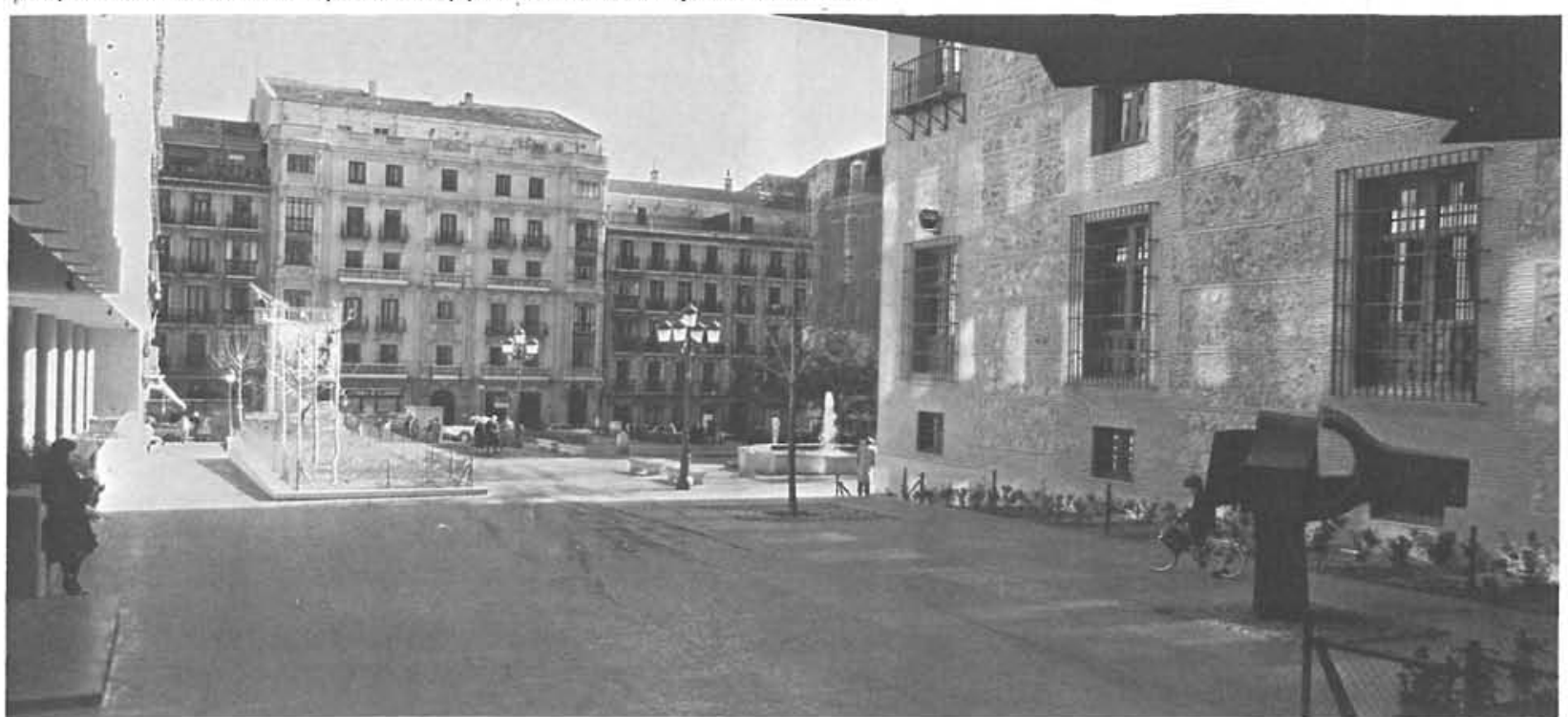

